\title{
Selection and Application of Synthetic versus Natural Emollients in the Formulation of Skin Care Products
}

\author{
ANCA MARIA J UNCAN*, CLAUDIU MORGOVAN, LUCA LIVIU RUS \\ Lucian Blaga University, Faculty of Medicine, Preclinical Department, 2A Lucian Blaga Str., 550169, Sibiu, Romania
}

\begin{abstract}
Two emollient ingredients with proven sensorial properties were slected for the development of a hand cream cosmetic formulations, and comparatively analysed. A synthetic oil (Polydecene) and a natural blend (J ojoba Esters and Acacia Decurrens Flower Wax and Helianthus Annuus (Sunflower) Seed Wax and Polyglycerin-3) were incorporated in cosmetic formulations for hand care. The aim of this study was to evaluate the quality control and the cosmetic qualities of the developed formulations, comparatively, of topical applied synthetic oil versus a natural origin wax blend.
\end{abstract}

Keywords: synthetic oil, natural emollients, xerotic skin, cosmetic emulsion

Cosmetics are commercially available products, that are used to improve the appearance of the skin [1-4]. Firstly, for a developed cosmetic formula to fulfill all the requirements, it is necessary to have a suitable vehicle (that encompasses emollients, moisturizers, preservatives, perfumes, colorants) and to include in its formulation all the active ingredients (UV filters, botanical or biotechnological extracts), necessary to attain what is claimed by its advertising [5-11].

The word emollient is a Latin derivation and implies a material that softens and smoothes the skin, both to the touch and to the eye. Emollients should have the effect of reducing the clinical signs of dryness, such as roughness or scaling, and improving sensations, such as itching and tightness [12-14].

The constituent ingredients of emollients do vary, however, most will have some quantity of lipid in them. Lipid is a broad term used to describe fats, waxes and oils. Lipids are essential components for human health $[12,15]$.

Most animal fats are now rarely used, the exception being lanolin. Waxes include beeswax. The most common type of lipid used is oil, examples of which include vegetable oil, petrolatum and synthetic oils such as polysiloxane. Lipids are combined with a range of other substances to produce the vast array of emollients available. Table 1 lists the main emollient substances $[12,16]$.

The inclusion of emollients in cosmetic emulsions is a common practice, independent of the final use of the emulsion. Considering their action on the skin, emollients contribute to water retention by the stratum corneum (SC). They result in a smoother, more elastic, and lubricated skin, and imparta pleasantand comfortable skin feel. Lipophilic emollients offer a wide variety of sensations when applied to the skin (waxy, greasy, oily, dry, astringent, sticky, velvety, etc.) and may have great incidence on the sensory characteristics of the cosmetic emulsions in which they are included. Emollients also have major incidence on the physic-chemical properties, such as consistency and spreadability of the emulsions in which they are included. These characteristics are very important to achieve adequate efficacy and user acceptance of the products [17].

Emollients are safe to use and cause little concern with regard to tolerability. The use and amounts, especially of emollient oils, are considered less risky to adjust in a formula when fine-tuning it for skin feel $[18,19]$.

Hydrocarbon-containing materials, such as petroleum jelly and mineral oil, are widely used in topical skin and mucosal preparation [20]. Simple emollients leave a fine occlusive layer of non-physiological lipid or oil, such as petrolatum or mineral oil, over the skin surface, thereby reducing water loss from the SC [21].

The popularity of mineral oil as a cosmetic ingredient emerged in the last quarter of the nineteenth century because of its low cost and abundant supply. In the first quarter of the twenty-first century, we see a back-to-nature movement that is purely based on the perception of the consumer that anything derived from nature is better, safer and more efficacious, whereas anything synthetic is chemical, dangerous and toxic. Table 2 lists a number of differences and similarities between vegetable oils and mineral oils used in cosmetics [22].

Many common natural oils such as rapeseed oil, sunflower oil and soybean oil are rich in polyunsaturated fatty acids, mainly linoleic (18:2n-6) and linolenic (18:3n3) acids. These natural oils are of significant nutritional importance and are also desirable emollients for skin care applications [23].

One of the most used natural oil in cosmetic creams is grape seed oil. The oil extracted from grape seeds has exceptional therapeutic properties [24].

Comprehensive in vivo investigations concerning the penetration behaviour of oils are still lacking, whereas the assumption that paraffin oil clogs the pores and prevents the skin from breathing, while vegetable oils penetrate deeper is commonly spread in literature [25].

\begin{tabular}{|c|l|}
\hline Astringent Emollients & Cyclomethicone, dimethicone, isopropyl myristate, octyl octanoate \\
\hline Dry Emollients & Decyl oleate, isopropyl palmitate, isostearyl alcohol \\
\hline Fatting Emollients & Castor oil, glyceryl stearate, jojoba oil, octyl stearate, propylene glycol \\
\hline Protective Emollients & Disopropyl dilinoleate, isopropyl isostearate \\
\hline Protein Rejuvenators & Collagen, elastin, keratin \\
\hline
\end{tabular}

Table 1

COMMON SUBSTANCES WITH EMOLLIENT PROPERTIES 


\begin{tabular}{|c|c|c|}
\hline & Vegetable oils & Mineral oil \\
\hline Origin & Plant-derived & $\begin{array}{l}\text { Animal-derived (fossil } \\
\text { plankton and algae) }\end{array}$ \\
\hline Production volume & Low to medium & High \\
\hline Production cost & Medium to high & Low \\
\hline Physical appearance & Yellowish to brown & Colourless \\
\hline $\begin{array}{l}\text { Chemical treatment } \\
\text { during manufacturing }\end{array}$ & $\begin{array}{l}\text { Mainly pressing (fixed oil) or } \\
\text { heating (volatile oils) }\end{array}$ & $\begin{array}{l}\text { Sulphuric acid and/or } \\
\text { hydrogenation }\end{array}$ \\
\hline Chemical stability & $\begin{array}{l}\text { Often sensitive to oxidation and } \\
\text { occasionally to light }\end{array}$ & Inert \\
\hline Biological activity & $\begin{array}{c}\text { Variable, depending on active } \\
\text { ingredients }\end{array}$ & Skin: moisturization \\
\hline Toxicology & $\begin{array}{c}\text { Variable, depending on active } \\
\text { ingredients }\end{array}$ & $\begin{array}{c}\text { Non-toxic, GRAS (Generally } \\
\text { Regarded As Safe) }\end{array}$ \\
\hline
\end{tabular}

Table 2

DIFFERENCES AND SIMILARITIES OF VEGETABLE OILS AND MINERAL OILS

\section{Experımental part}

Materials and methods

Emollient ingredients selection criteria for the development of the cosmetic formulations

Two emollient ingredients with proven sensorial properties were slected for the development of hand cream cosmetic formulations, and comparatively analysed- a synthetic oil- Nexbase 2006 FG (Hydrogenated Polydecene) and a blend of vegetable waxes- Acticire (J ojoba Esters and Acacia Decurrens Flower Wax and Helianthus Annuus (Sunflower) Seed Wax and Polyglycerin-3).

For the development of the first formulation incorporating the synthetic oil, it has been proposed the use of Hydrogenated Polydecene. This emollient has been selected for the following cosmetic qualities:

Sensorial Purity:

- Tasteless,

- Odourless,

- Limpid, colourless and transparent

High stability:

- Oxydation stability (saturated oligomers)

- Photostability (transparent against UV)

- Temperature stability (from -60 to $220^{\circ} \mathrm{C}$ )

- pH stability (inert molecules)

High compatibility:

- Soluble in most of non polar solvents (ethers, esters, fatty alcohols, saturated and unsaturated triglycerides, mineral oils and cyclomethicones)

- Compatibility with most packaging raw materials

Nexbase is suitable for any type of cosmetic products: emulsions, gels, serums, sticks, etc. It is a synthetic oil, also called Poly-alpha-olefin (PAO) and it's composition is presented in table $3[26,27]$.

\section{Table 3}

COMPOSITION OF NEXBASE NEXBASE 2006 FG (HYDROGENATED POLYDECENE)

\begin{tabular}{|c|c|}
\hline \multicolumn{2}{|l|}{$\begin{array}{l}\text { Composition } \\
\text { Oligomer distribution }\end{array}$} \\
\hline $\mathrm{C} 30(\%)$ & $13-37$ \\
\hline $\mathrm{C} 40(\%)$ & $35-70$ \\
\hline $\mathrm{C50}(\%)$ & $9-25$ \\
\hline $\mathrm{C} 60(\%)$ & $1-7$ \\
\hline $\mathrm{C70}(\%)$ & $0-2$ \\
\hline \multicolumn{2}{|l|}{ Residues } \\
\hline Hydrocarbons below trimers (\%) & $<1.5$ \\
\hline
\end{tabular}

For the development of the second formulation it has been proposed the use of a blend of vegetable waxesActicire (J ojoba Esters and Acacia Decurrens Flower Wax and Helianthus Annuus (Sunflower) Seed Wax and Polyglycerin-3). This emollient has been selected due to the cosmetic characteristic features it possesses:

- $100 \%$ of natural origin

- improves stability of formulation

- allows innovative formulation

- improves sensoriality

- brings durable moisturization and comfort

J ojoba wax is the only liquid wax that exists, it is liquid because it is composed of esters of unsaturated fatty alcohol with an unsaturated fatty acid. Sunflower seed wax is a hard wax composed of fully saturated mono esters, it presents excellent thermal stability. And finally Mimosa wax, which is a co-product of the perfumery industry, is not surprisingly a rather sweet smelling ingredient which is relatively soft compared to the others. It has a melting point of about $60^{\circ} \mathrm{C}$ and has a more complex composition which includes long chain esters, hydrocarbons and a smaller amount of triterpenoid alcohols.

Each ingredient of the natural blend is different and can have a positive role to play in a final cosmetic (fig.1.) [28].

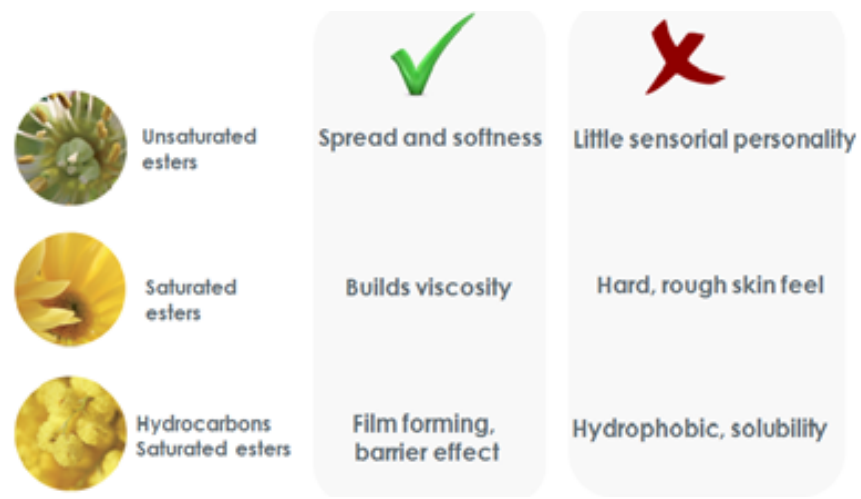

Fig. 1. Composition of Acticire (Jojoba Esters and Acacia Decurrens Flower Wax and Helianthus Annuus (Sunflower) Seed Wax and Polyglycerin-3)

\section{Preparation of the cosmetic formulations}

The ingredients used in the hand cream formulations were: deionised water, Propanediol (DuPont, USA), Glycerin (Dr. Straetmans GmbH, Germany), EDTA (Brenntag SRL, Romania), and a preservative (Phenoxyethanol, Methylparaben, Ethylparaben, Propylparaben, Buthylparaben, Isobutylparaben) (Seppic, 


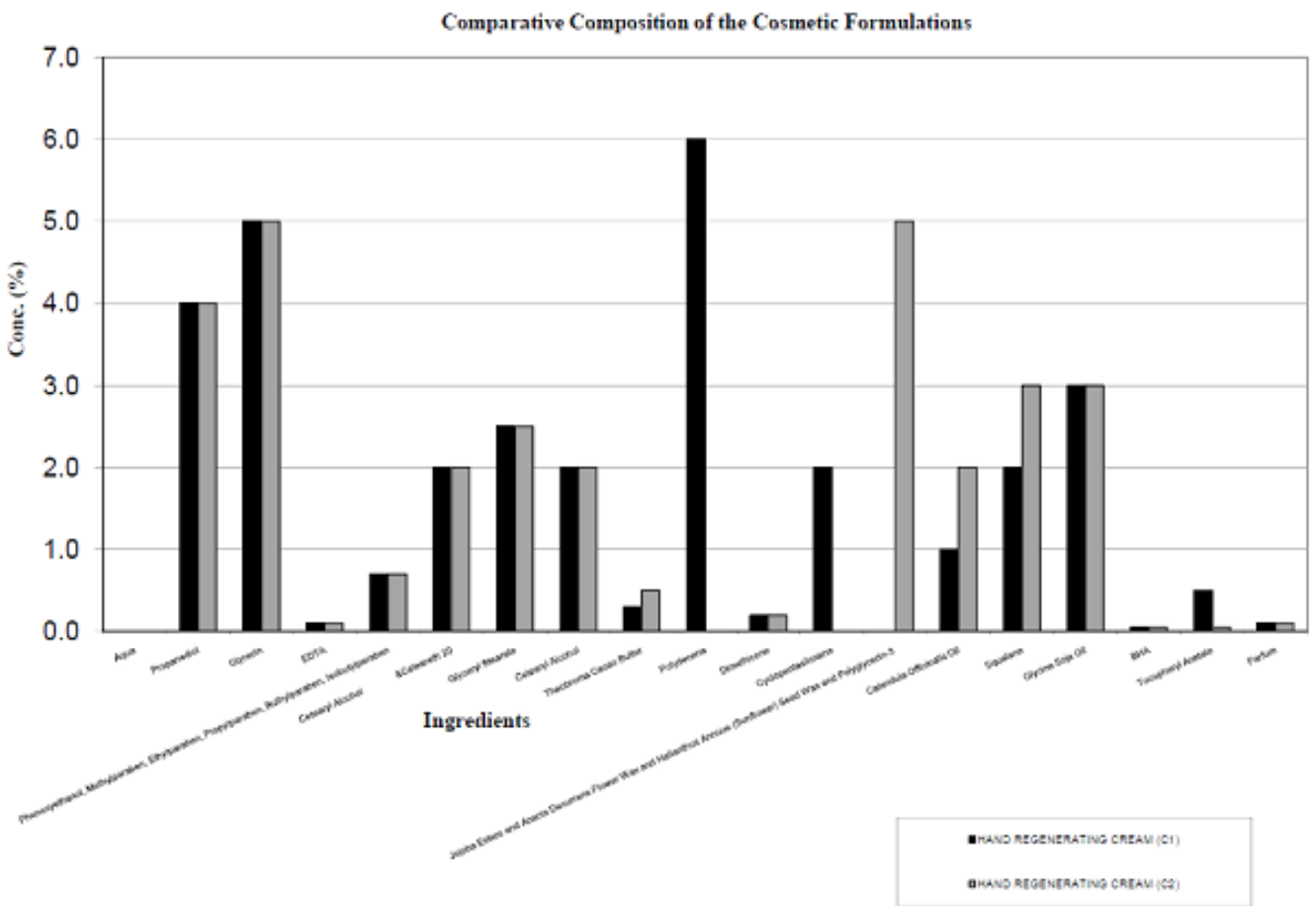

Fig. 2. Comparative Composition of the Hand Cream Formulations

Glyceryl Stearate (ISP, UK), Cetearyl Alcohol (Cognis, Germany), Theobroma Cacao Butter (Sophim, France), Polydecene (J an Dekker, Nederland) or J ojoba Esters and Acacia Decurrens Flower Wax and Helianthus Annuus (Sunflower) Seed Wax and Polyglycerin-3 (Gattefosse, France), Dimethicone (Dow Corning, USA), Cyclopentasiloxane (Dow Corning, USA), Calendula Officinalis Oil (Sophim, France), squalane (Sophim, France), Glycine Soja Oil (Sophim, France), BHA (Jan Dekker, Nederland), Tocopheryl Acetate (BASF, Germany), and parfum (CPL Aromas, UK).

The composition of the two studied creams is presented, by comparison in figure 2 . The different ratios between lipophilic and hydrophilic components are noticed.

Manufacturing procedure: Phase $\mathrm{A}$ (aquaous Phase) was heated up to $80^{\circ} \mathrm{C}$. Phase $B$ was heated up to $75-80^{\circ} \mathrm{C}$. Phase A was emulsyfied into Phase B under stirring and homogenized for 1-2 min., using an ultra turrax. Medium stirring was performed for cooling down. Phase $C$ (Tocopheryl Acetate) and Phase D (parfum) were added below $40^{\circ} \mathrm{C}$ and cooling down was performed under stirring.

\section{Relevant Physico-chemical Characteristics}

Quality control consisted of the following determinations:

The appearance, color and odor were tested organoleptically.

$\mathrm{pH}$ determination was performed using a $\mathrm{pH}$ meter (Mettler Toledo (Schwerzenbach, Switzerland)).

Viscosity was performed using a HAAKE Viscotester VT550 (spindle $R=6$, shear rate $D=5 \mathrm{~s}^{-1}$, temperature $\mathrm{T}=20^{\circ} \mathrm{C}$ ).

\section{Cosmetic quality assessment}

The self-evaluation study revealed the cosmetic qualities of the cosmetic formulations, after product use. The typological characteristics of the subjects (age, phototype) were defined.

Perceived skin feel attributes of creams (appearance rub-in, absorption, appearance of skin, immediate and delayed afterfeel) have been evaluated. The cosmetic qualities were assessed, using a target questionnaire, applied for ten subjects, using comparatively the cosmetic cream after product use [29].
The specific inclusion criteria, defined in the protocol, were the following ones:

- age: $20-60$ years old;

- sex: female;

-phototype (Fitzpatrick): I to V.

All subjects included corresponded to these specific inclusion criteria. The experimental area corresponded to the usual application site of the product. The panel corresponded to the population likely to use the product: the main inclusion criteria corresponded to the target market of the product.

Statistical analysis using Microsoft Excel was undertaken.

\section{Results and discussions}

The synthetic oil used in the developed cosmetic formula- Nexbase (Polydecene) is suitable for any type of cosmetic products: emulsions, gels, serums, sticks, etc. In any types of cosmetic products, Polydecene will contribute to the effectiveness of the product while offering a light and pleasant application.

Acticire (J ojoba Esters and Acacia Decurrens Flower Wax and Helianthus Annuus (Sunflower) Seed Wax and Polyglycerin-3) is of natural origin and combines sensorial, compatibilizing, and active properties.

Cosmetic formulations, containing a majority of vegetable oils, frequently present a rich feel during application yet a dry afterfeel within several minutes, giving an impression of lack of moisturization and comfort. This is principally due to the absence of a protecting film on the surface of the skin. Vegetable waxes can protect the skin however, in their native form, they are difficult to formulate and often recrystallize in the formulations. They also present a rough afterfeel on the skin. In Acticire (J ojoba Esters and Acacia Decurrens Flower Wax and Helianthus Annuus (Sunflower) Seed Wax and Polyglycerin-3), the crystals, smaller and rounder, form a smoother film leading to a softer touch. It has been demonstrated, that Acticire improves application and afterfeel. The long lasting comfort sensation created by the natural blend comes from the perceptible yet light film on the skin. This is particularly suitable for those skins that want moisturization and nutrition without any feeling of heaviness. 


\begin{tabular}{|c|c|}
\hline Test & Admissibility conditions \\
\hline $\begin{array}{c}\text { Hand Cream } \\
\text { NEXBASE (HYDROGENATED } \\
\text { POL YDECENE) }\end{array}$ & $\begin{array}{c}\text { Hand Cream } \\
\text { ACTICIRE (JOJOBA ESTERS AND ACACIA } \\
\text { DECURRENS FLOWER WAX AND } \\
\text { HELIANTHUS ANNUUS (SUNFLOWER) SEED } \\
\text { WAX AND POLYGLYCERIN-3 }\end{array}$ \\
\hline Appearance & homogeneous cream \\
\hline Odor & characteristic odor, parfumed \\
\hline Color & white-beige \\
\hline $\mathrm{pH}$ & $5,5-6,0$ \\
\hline Viscosity & $25.000 \mathrm{mPas}$ \\
\hline
\end{tabular}

Table 4

PHYSICO-CHEMICAL CHARACTERISTICS OF THE DEVELOPED HAND CREAM CONTAINING THE SYNTHETIC OIL NEXBASE ((HYDROGENATED POLYDECENE) AND THE NATURAL BLEND ACTICIRE (J OJ OBA ESTERS AND ACACIA DECURRENS FLOWER WAX AND HELIANTHUS ANNUUS(SUNFLOWER) SEED WAX AND POLYGLYCERIN-3)

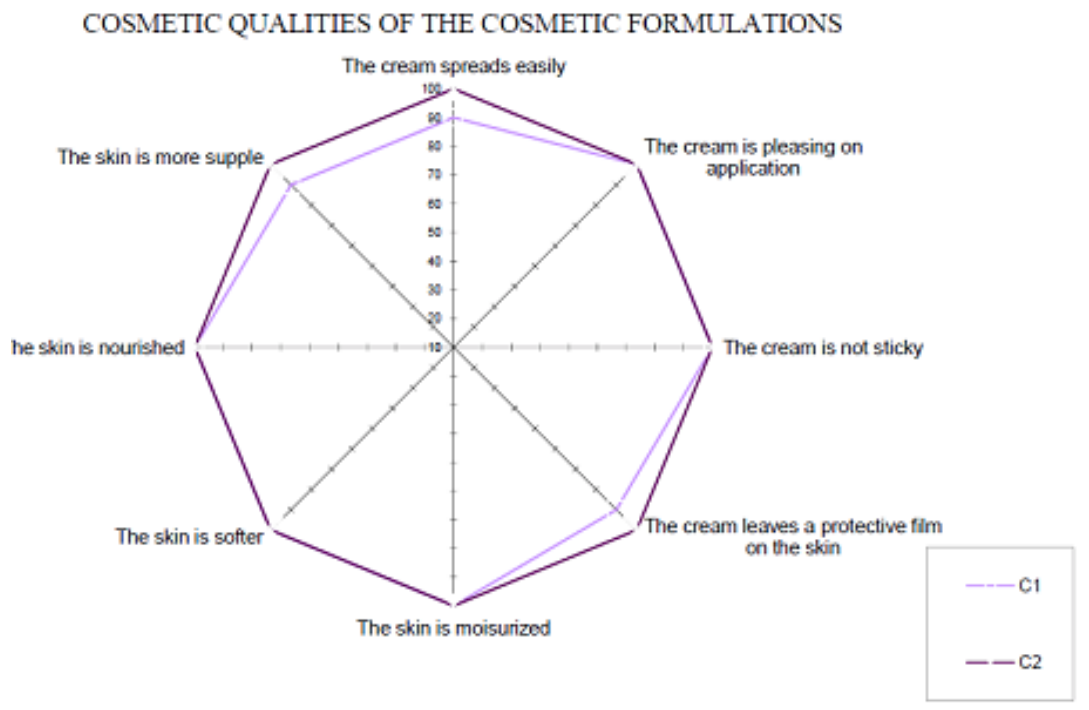

Fig. 3. Comparative sensorial profile of the developed formulations containing synthetic oil and the active texturizing agent
Quality control of the developed cosmetic creams revealed: achieving an acceptable cosmetic preparation with elegant appearance and appropriate physicochemical and pharmacotechnical ( $\mathrm{pH}$, viscosity) characteristics. The determination results are shown in table 4.

The self-evaluation study highlighted the cosmetic qualities of the cosmetic formulations, after application. The typological characteristics of the subjects (age, phototype) were considered. The products were applied to each subject individually, once, on the forearm.

To highlight the added value provided by Acticire ( $)$ ojoba Esters and Acacia Decurrens Flower Wax and Helianthus Annuus (Sunflower) Seed Wax and Polyglycerin-3), by comparison to the synthetic oil Polydecne, it was compared two emulsions, one containing $5 \%$ natural blend and the other $6 \%$ synthetic oil. Each subject had to evaluate the perception of the creams, and several criteria were investigated regarding the comfort of application, and the aspect of the skin after product use. The results clearly show a very good overall satisfaction level and a strong moisturizing effect of Acticire confirmed by $100 \%$ of the subjects (fig. 3.).

\section{Conclusions}

The differences between vegetable oils and synthetic oil are only marginal. The efficacy of mineral oil is mainly on top of the skin (where it leads to emolliency and skin moisturization via occlusivity), whereas vegetable oils and waxes as a class of chemicals are smaller and, even within a single oil, more chemically diverse; hence, they offer less occlusivity but a higher biological efficacy in specific applications and cosmetic categories.

The comparison of both studied formulation showed that the developed creams are acceptable cosmetic preparation with elegant appearance and appropriate physico-chemical and pharmacotechnical ( $\mathrm{pH}$, viscosity) characteristics.

Cosmetic quality assessment of the studied cosmetic formulations confirmed that both emollient ingredients can be used in skin care to improve moisturization and texture, and can be formulated easily in any kind of emulsion.

Acknowledgement: Special thanks are extended to Azelis Romania $S R L$ for providing cosmetic ingredients used for the development and formulation of the cosmetic formulations.

\section{References}

1.J UNCAN, A. M., HODISAN, T., Rev. Chim. (Bucharest), 62, no. 4, 2011, p. 415.

2.JUNCAN, A. M., RUS, L. L., Mat. Plast., 55, no. 3, 2018, p. 426.

3.JUNCAN, A. M., Mat. Plast., 55, no. 4, 2018, p. 644.

4.MUNTEAN, A. C., JUNCAN, A. M., MOISA, D. G., VONICA, A. L., RUS, L. L., MORGOVAN, C., GLIGOR, F. G. BUTUCA, A., STANILA, A., Mat. Plast., 56, no. 2, 2019, p. 360.

5.SALVADOR, A. CHISVERT, A., Analysis of Cosmetic Products, $1^{\text {st }}$ Edition, Elsevier, Amsterdam, 2007, p. 324. 
6.MORGOVAN, C., GHIBU, S., JUNCAN, A. M., RUS, L. L., BUTUCA, A., VONICA, L., MUNTEAN, A., MOS, L., GLIGOR, F., OLAH, N. K., Farmacia, 67, 3, 2019, p. 537.

7.JUNCAN, A. M., HORGA, E. C., HODISAN, T., Studia UBB Chemia, 56, 2, 2011, p. 195.

8.DANCIU, C., BIRIS, M., BOGLARKA, B., CSANYI, E., ZINUCA PAVEL, I., POP, G., SOICA, C., CEUTA, L., NITA L., MORGOVAN, C., STOIAN D., Rev. Chim. (Bucharest), 66, no. 7, 2015, p. 1038.

9.POPESCU, C., POPESCU, C., POPESCU, B., DAAS, D., MORGOVAN, C., OLAH, N. K., Farmacia, 62, 4, 2014, p. 743.

10.J UNCAN, A. M., RUS, L. L., GLIGOR, F. G., MORGOVAN, C, Rev. Chim. (Bucharest), 70, no. 2, 2019, p. 555.

11.J UNCAN, A. M., FETEA, F., SOCACIU, C., ENVIRON. ENG. MANAG. J., 13,1, 2014, p. 105.

12.PENZER, R., Dermatol. Nurs., 11, 4, 2012, p. 1.

13.LODEN, M., Clin. Dermatol., 2003, 21, p. 145.

14.CAMARGO, F. B., GASPAR, L. R., CAMPOS, P. M., J. Cosmet. Sci., 62, 2011, p. 361.

15.IOSIF, L., GAMAN, L., CRIHANA, I., KOVACS, E., STOIAN, I., LUPESCU, O., Rev. Chim. (Bucharest), 67, no. 12, 2016, p. 2638.

16.KRAFT, J. N., LYNDE, C. W., Skin Therapy Lett., 10, 5, 2005, p. 1. 17.PARENTE, M. E., GAMBARO, A., SOLANA, G., J. Cosmet. Sci., 56, 2005, p. 175.

18.KOWNACKI, S., Nurs. Times., 105, 28, 2009, p.18.
19.DEDEREN, C., DONAHUE, J., VERBOOM, C., Cosmetics\&Toiletries Magazine, 128, 12, 2013, p. 884.

20.BROWN, B. E., DIEMBECK, W., HOPPE, U., ELIAS, P. M., J. SOC. Cosmet. Chem., 4, 6, 1995, p. 1.

21.MONCRIEFF, G., CORK, M., LAWTON, S., KOKIET, S., DALY, C., CLARK, C., Clin. Exp. Dermatol., 38, 3, 2013, p. 231.

22.RAWLINGS, A. V., LOMBARD, K. J., Int. J. Cosmet. Sci., 34, 2012, p. 511.

23.ALANDER, J., ANDERSSON, A.-C., LINDSTRÖM, C., Lipid Technol., 18, 10, 2006, p. 226.

24.TOCIU, M., TODASCA, M. C., MIHALACHE, M., ARTEM, V., HANGANU, A., Rev. Chim. (Bucharest), 69, no. 1, 2018, p. 130.

25.PATZELT, A., LADEMANN, J., RICHTER, H., DARVIN, M. E., SCHANZER, S., THIEDE, G., STERRY, W., VERGOU, T., HAUSER, M., Skin. Res. Technol., 18, 3, 2012, p. 364.

26.J UNCAN, A. M., BUTUCA, A., RUS, L., L., MORGOVAN, A., C., Proceedings of The Romanian National Congress of Pharmacy- $17^{\text {th }}$ Edition $21^{\text {st }}$ Century Pharmacy-Between Intelligent Specialization and Social Responsibility, Filodiritto Publisher (Bucharest, Romania, $26^{\text {th }}$ 29 $9^{\text {th }}$ September 2018), ISBN 978-88-85813-28-1, p. 107.

27.GRAIZEAU, G., DE J AGER, H., Ideal Inert Ingredient Nexbase Series, MK Presentation, 2009, p. 4.

28.GATTEFOSSE, Acticire Preserntation, MK Brochure, 2015, p. 5. 29.BAGATIN, E., MIOT, H. A., An. Bras. Dermatol., 88, 1,2013, p. 69.

Manuscript received: 21.08 .2018 